\title{
Perfil do consumo e conhecimento sobre fruteiras nativas e exóticas
}

\author{
Consumption and knowledge profile of native and exotic fruits \\ Perfil de consumo y conocimiento de frutas nativas y exóticas
}

Recebido: 03/10/2021 | Revisado: 13/10/2021 | Aceito: 21/10/2021 | Publicado: 22/10/2021

\author{
Marcelo Almeida de Oliveira Junior \\ ORCID: https://orcid.org/0000-0002-1027-2777 \\ Universidade de São Paulo, Brasil \\ E-mail: Marcelo_oli@usp.br \\ Matheus Luís Docema \\ ORCID: https://orcid.org/0000-0003-2140-4488 \\ Universidade de São Paulo, Brasil \\ E-mail: matheus.docema@gmail.com \\ Marcela Sant'Anna Cordeiro da Silva \\ ORCID: https://orcid.org/0000-0002-2851-7525 \\ Universidade de São Paulo, Brasil \\ E-mail: marcela.sce@gmail.com \\ Michael Willian Rocha de Souza \\ ORCID: https://orcid.org/0000-0003-4684-4842 \\ Universidade de São Paulo, Brasil \\ E-mail: michael.willian@usp.br
}

\begin{abstract}
Resumo
Terceiro maior país em produção de frutas frescas no mundo, o Brasil destaca-se por apresentar ampla capacidade de adaptação produtiva de fruteiras exóticas devido, principalmente, às suas condições edafoclimáticas que somados a práticas culturais já estabelecidas, permitem alcançar altas produções. Além disso, o país é detentor de uma das maiores agrobiodiversidades mundiais, possuindo espécies nativas frutíferas com alto potencial de exploração do consumo. Porém, muitas vezes essas frutas não recebem o devido valor, sendo negligenciadas pelo desconhecimento popular, e, consequentemente, apresentam baixa participação no comércio de frutas do Brasil. Diante deste cenário, o presente trabalho teve por objetivo identificar o padrão de consumo de frutas, analisar o conhecimento popular sobre fruteiras exóticas e nativas e verificar a potencialidade de inserção de espécies nativas do Brasil no mercado de frutas. Observouse que, o consumo de frutas é inferior ao recomendado pela Organização Mundial da Saúde (OMS), sendo composto em sua maioria de fruteiras exóticas adquiridas em supermercados. Apesar da falta de entendimento dos termos de classificação de frutas quanto ao centro de origem, os participantes da pesquisa, compreendidos majoritariamente por pessoas que possuem ensino superior, conhecem quais espécies são pertencentes à flora brasileira e quais foram introduzidas no território nacional. Além disso os entrevistados demonstram consciência da importância das espécies nativas e dos entraves que impedem a inserção no mercado em maiores quantidades, afirmando que gostariam de consumir mais frutas nativas, o que demonstra a potencialidade da fruticultura nacional.
\end{abstract}

Palavras-chave: Fruticultura; Mercado de frutas; Percepção pública.

\begin{abstract}
The third-largest country in the production of fresh fruit in the world, Brazil stands out for having an ample capacity of adaptation of exotic fruit trees, due to its edaphoclimatic conditions, which added to already established cultural practices, allows the achievement of high yields. In addition, the country has one of the largest agrobiodiversities in the world, having native fruit species with high potential for consumption exploitation, however, many times these fruits do not receive any value and are neglected by popular ignorance, presenting low participation in the fruit market. Therefore, the present study aimed to identify the pattern of fruit consumption, analyze popular knowledge about exotic and native fruit trees and verify the potential for insertion of native species from Brazil in the fruit market. It was observed that the consumption of fruit is lower than that recommended by the World Health Organization (WHO), is composed mostly of exotic fruit acquired in supermarkets. Despite the lack of understanding of the terms of fruit classification based on the center of origin, the research participants, consisted mostly of people with higher education, understand which species belong to the Brazilian flora and which ones have been introduced in the national territory, and demonstrate awareness of the importance of native species and the barriers that prevent insertion in the market in larger quantities and affirm that they would like to consume more native fruits, which demonstrates the potential of Brazilian fruits.
\end{abstract}

Keywords: Fruit crops; Fruit market; Public perception. 


\section{Resumen}

Brasil es el tercer productor mundial de frutas frescas en el mundo, destacándose por tener una amplia capacidad de adaptación productiva de frutales exóticos, debido principalmente a sus condiciones edafoclimáticas, que sumadas a las prácticas culturales, permiten lograr altas producciones. Adicionalmente, Brasil es dueño una de las mayores riquezas en agrobiodiversidad, contando con especies de frutas nativas con alto potencial de explotación para el consumo. Esas frutas muchas veces no reciben el valor debido, siendo desconocidas para una representativa parte de la población y como consecuencia, teniendo baja participación en el comercio de frutas brasileño. Ante este escenario, el presente estudio tuvo como objetivo identificar el patrón de consumo de frutas, analizar el conocimiento popular sobre frutales exóticos y nativos, y verificar el potencial de inserción de especies nativas de Brasil en el mercado de frutas. Se observó que el consumo de fruta es menor al recomendado por la Organización Mundial de la Salud (OMS), compuesto en su mayoría por frutas exóticos adquiridos en supermercados. A pesar de la falta de entendimiento de los términos de clasificación de frutas en cuanto al centro de origen, los participantes de la investigación, principalmente comprendido por personas con educación superior, identifican qué especies pertenecen a la flora brasileña y cuáles fueron introducidas en el territorio nacional, comprenden la importancia de las especies nativas y las barreras que impiden su ingreso al mercado en mayores proporciones, manifestando que les gustaría consumir más frutas nativas, lo que demuestra el potencial de las fruticultura brasilera.

Palabras clave: Fruticultura; Mercado de frutas; Percepción publica.

\section{Introdução}

O Brasil é um dos principais países produtores de frutas do mundo e a fruticultura é uma atividade agrícola em ascensão. Esse crescimento ocorre devido à grande extensão territorial e excelente localização geográfica do país. Além do cultivo de frutas tropicais e outras tradicionais no país, o cultivo de frutas de clima temperado tem sido cada vez maior no Brasil, devido, principalmente, à alta capacidade das espécies exóticas de se adaptarem às diversas condições de cultivo (Rodrigues et al., 2012). Em 2018, a produção de frutas frescas atingiu 40 milhões de toneladas, o que permitiu o país ser considerado um dos principais produtores do mundo, ocupando o terceiro lugar no ranking de produção de frutas frescas (Anuário Brasileiro de Hortifruti, 2020).

Dentre essas frutíferas, destacam-se as espécies exóticas que foram introduzidas no Brasil e que se adaptaram perfeitamente às condições edafoclimáticas do país, sendo produzidas e consumidas em larga escala. Entre as espécies frutíferas que apresentam maiores relevâncias econômicas e alimentares destacam-se as laranjeiras e as bananeiras. O Brasil é o maior produtor mundial de laranja doce e o terceiro maior produtor de bananas, sendo cultivadas anualmente 17,0 e 6,7 milhões de toneladas, respectivamente, destas frutas (FAO, 2020).

A biodiversidade brasileira o torna um dos países mais importantes do mundo em termos de conservação e fonte de recursos naturais, possuindo entre $15 \%$ e $20 \%$ da flora mundial distribuídas nos mais diversos biomas, dos quais destacam-se a Amazônia, o Cerrado e a Mata Atlântica. Estima-se que o Brasil possua mais de 46 mil espécies vegetais que compõem a sua rica biodiversidade, sendo que $71 \%$ destas espécies são pertencentes às angiospermas (Coradin et al., 2011; Flora do Brasil, 2020).

De acordo com Lorenzi et al. (2015), as espécies frutíferas nativas do Brasil ainda não são produzidas em escala comercial e o mercado ainda é restrito e incipiente. Entretanto, a agregação de valor destas frutíferas aliado a capacidade de geração de renda aos agricultores podem ser importantes catalizadores para a disseminação da produção, distribuição e consumo das frutas nativas.

Apesar disso, o cenário atual da inserção de nativas no mercado é promissor, uma vez que fruteiras brasileiras vêm se destacando e despertando interesses aos produtores e consumidores. O açaí (Euterpe oleracea Mart.), fruta nativa da Amazônia, é um exemplo de potencialidade e sua produção atingiu 1,3 milhão de toneladas no ano de 2017, representando um aumento de 22,2\% em relação ao ano anterior (IBGE, 2017). O ganho do mercado internacional e nacional pelas frutas nativas é resultado da procura por alimentos de alto valor nutritivo e de suas propriedades nutracêuticas, uma vez que apresentam elevada capacidade antioxidante e concentrações de vitaminas importantes para a saúde humana (Rufino et al., 2010; Alves et al., 2017). Neste 
contexto, o objetivo do trabalho foi compreender o padrão de consumo de frutas exóticas e nativas pela parcela entrevistada, assim como, analisar o conhecimento sobre o tema, além de identificar a potencialidade de frutas nativas a serem introduzidas no mercado brasileiro e pontuar quais os maiores entraves na visão do consumidor.

\section{Metodologia}

O trabalho foi realizado com o intuito de entender a percepção pública sobre o consumo de frutas, nativas e exóticas, e identificar através do conhecimento popular, as potencialidades da introdução de frutíferas nacionais no mercado.

Foi realizado um questionário online com a utilização da plataforma Google ${ }^{\circledR}$ Formulários, onde obteve-se a participação de 283 pessoas não identificadas. Primeiramente, foram realizadas cinco questões relacionadas à caracterização socioeconômica dos participantes. Posteriormente, foram elaboradas 11 questões objetivas e subjetivas que ficaram disponíveis para respostas no período de 10 de maio a 10 de setembro de 2020. Foram elaboradas perguntas em relação a compra, consumo e conhecimento popular sobre frutas nativas e exóticas, assim como questões que buscassem o entendimento dos participantes sobre os termos de classificação das frutas quanto ao seu local de origem e o potencial mercado de frutas brasileiras. Após a obtenção dos dados, foram elaborados tabela e gráficos a fim de analisar de forma descritiva as respostas obtidas.

A seleção dos participantes foi realizada de forma aleatória, utilizando-se as mídias sociais para ampla divulgação do questionário online.

\section{Resultados e Discussão}

O Brasil destaca-se entre os maiores produtores de frutas do mundo, sendo que sua posição geográfica e o clima favorável são alguns dos fatores que elevam o país na posição do ranking mundial, permitindo-se que fruteiras de clima tropical, subtropical e até mesmo as que necessitam de frio, como as temperadas, associados de técnicas culturais já consolidadas no país, obtenham altas produções alavancando o PIB nacional e gerando renda a pequenos, médios e grandes produtores (Fachinello et al., 2011; Santos et al., 2018).

Apesar da relevância na produção das espécies frutíferas exóticas, o país também apresenta um elevado potencial de exploração econômica das inúmeras espécies nativas que compõem sua flora. Entretanto, a produção e consumo se mantêm majoritariamente nas frutas de origens estrangeiras, das quais estão integradas à nossa cultura e hábito alimentar. Porém, algumas espécies tropicais nativas alcançaram o sucesso na participação do agronegócio brasileiro, tanto em produção quanto em consumo. No entanto, espécies que apresentam grande potencial para a economia e diversificação de consumo são, infelizmente, negligenciadas pela população que, na grande maioria das vezes, não possui o conhecimento da origem do que realmente é produzido, interferindo assim na valorização de produtos nacionais.

\section{Perfil Socioeconômico dos participantes da pesquisa}

A partir de perguntas elaboradas no questionário foi possível traçar o perfil socioeconômico dos participantes. A idade dos entrevistados foi variável, compreendendo desde menores de 18 anos a maiores de 50 anos, sendo as parcelas mais representativas, aquelas que compreendem de 18 a 42 anos, totalizando $79 \%$ dos entrevistados. Quanto ao gênero, $43 \%$ dos participantes são do sexo masculino e 57\% do sexo feminino (Tabela 1). 
Tabela 1. Idade, gênero, grau de escolaridade, renda mensal e áreas de atuação dos participantes da pesquisa, expressos em porcentagem (\%).

\begin{tabular}{llc}
\hline Idade & N & Porcentagem (\%) \\
\hline Menos de 18 anos & 9 & 3 \\
Entre 18 e 25 anos & 63 & 22 \\
Entre 26 e 33 anos & 125 & 44 \\
Entre 34 e 42 anos & 37 & 13 \\
Entre 43 e 49 anos & 22 & 8 \\
50 anos ou mais & 27 & 10 \\
\hline
\end{tabular}

\begin{tabular}{llc}
\hline Gênero & N & Porcentagem (\%) \\
\hline Feminino & 160 & 57 \\
Masculino & 123 & 43 \\
\hline Grau de escolaridade & N & Porcentagem (\%) \\
\hline Ensino fundamental incompleto & 4 & 1 \\
Ensino fundamental completo & 4 & 1 \\
Ensino médio incompleto & 9 & 3 \\
Ensino médio completo & 25 & 9 \\
Superior incompleto & 36 & 13 \\
Superior completo & 54 & 19 \\
Pós-graduação em andamento & 75 & 27 \\
Pós-graduado & 76 & 27
\end{tabular}

\begin{tabular}{llc}
\hline Renda mensal & N & Porcentagem (\%) \\
\hline Não tenho nenhuma renda mensal & 40 & 14 \\
Menos que um salário-mínimo & 16 & 6 \\
Entre um e dois salários-mínimos & 81 & 29 \\
Entre três e quatro salários-mínimos & 78 & 28 \\
Mais que cinco salários-mínimos & 68 & 24 \\
\hline Áreas de atuação & N & Porcentagem (\%) \\
\hline Aposentados & 5 & 2 \\
Serviços & 13 & 5 \\
Tecnologias da informação e Comunicação (TIC) & 2 & 1 \\
Funcionário Público & 8 & 3 \\
Agricultura, Recursos florestais, Recursos pesqueiros e Veterinária & 67 & 24 \\
Produtor Rural & 5 & 2 \\
Educação & 28 & 10 \\
Negócios, Administração e Direito & 39 & 14 \\
Estudante (Graduação e Pós-Graduação) & 64 & 23 \\
Ciências sociais, Jornalismo e Informação & 2 & 1 \\
Saúde e Bem-estar & 18 & 6 \\
Engenharia, Produção e Construção & 8 & 3 \\
Ciências naturais, Matemática e Estatística & 12 & 4 \\
Desempregado & 10 & 4 \\
Artes e Humanidades & 2 & 1 \\
\hline
\end{tabular}

$\mathrm{N}$ : Número de indivíduos participantes.

Fonte: Autores. 
A maioria dos participantes iniciou e concluiu o ensino superior, perfazendo $73 \%$ dos 283 entrevistados com ingresso e conclusão, este cenário não é comum no Brasil e, possivelmente, o motivo pela alta taxa pode ser explicado pela divulgação da pesquisa através de mídias e grupos em aplicativos voltados à educação superior (Tabela 1). Em relação a renda mensal dos participantes foi observado que a grande maioria se enquadra nas classes E e D, segundo a classificação do Instituto Brasileiro de Geografia e Estatística (IBGE), e 24\% estão inseridas na classe C, recebendo mais que cinco salários-mínimos por mês (soma dos rendimentos da família).

Quanto a profissão dos participantes, mostrou-se ter uma grande variação, apesar de $23 \%$ estarem relacionados de alguma forma com ciências agrárias e $22 \%$ serem estudantes de graduação, mestrado, doutorado e pós-doutorado, foi possível obter uma considerável diversificação, tendo participação de profissionais de diferentes áreas (Tabela 1).

Consumo e conhecimento popular sobre frutas nativas e exóticas e potencialidade de inserção de frutas nativas no mercado brasileiro

Primeiramente, os participantes foram questionados sobre a frequência do consumo de frutas, onde apresentaram as maiores porcentagens aqueles que consomem de duas a três, de quatro a cinco e de seis a sete vezes por semana, com $26 \%, 28 \%$ e 30\% do total, respectivamente (Figura 1). Segundo a Organização Mundial da Saúde (OMS), a ingestão diária recomendada de frutas é de cerca de 400 gramas, o que seria equivalente a cinco porções diárias (Souza et al., 2019). Apesar da pesquisa não entrar em detalhes no consumo de frutas por porções diárias, é possível concluir que entre os 283 participantes, cerca de $72 \%$ não atingem a quantia recomendada de consumo. Silva \& Claro (2019), em sua pesquisa sobre consumo de frutas e hortaliças entre adultos nas capitais e distrito federal, concluíram que, apesar do aumento da ingestão de frutas/legumes/verduras (FLV) entre os anos de 2008 e 2016, a grande maioria da população ainda não consome as recomendações mínimas estabelecidas, necessitando ações de incentivos ao consumo.

Figura 1. Frequência do consumo de frutas dos participantes, em porcentagem (\%). Gráfico elaborado a partir das respostas obtidas na pergunta "Com que frequência você consome frutas?"

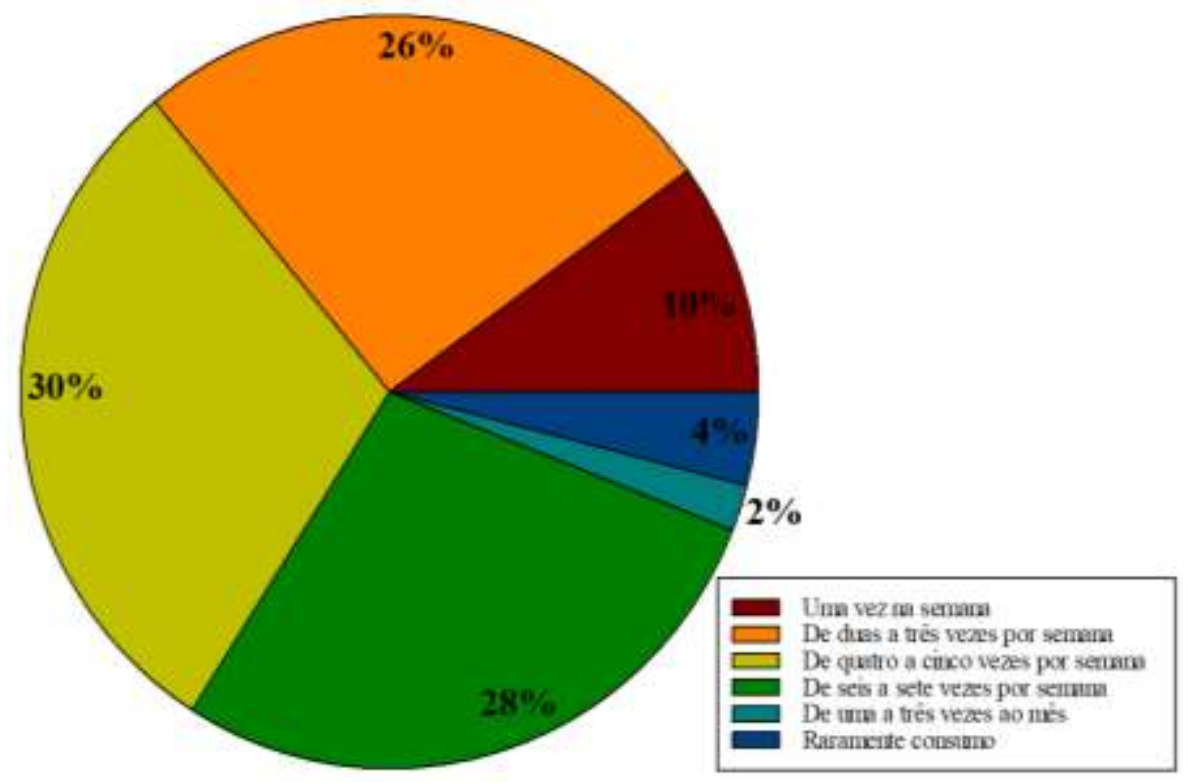

Fonte: Autores.

Dentre as principais frutas consumidas pelos participantes da pesquisa, a banana segue em primeiro no ranking com 
18,5\% do total, seguido pela maçã, com 14,1\%, e laranja com 12,2\%, sendo estas frutas de origem de outros países (Figura 2). Ambas apresentam grande produção no país, sendo que, laranja e banana asseguram o primeiro e segundo lugar no ranking de produção brasileira e a maçã o oitavo, no ano de 2018 (Anuário Brasileiro de Hortifruti, 2020). Segundo o IBGE (2018), as cinco frutas mais consumidas no brasil nos anos de 2017-2018 foram banana, laranja, melancia, maçã e mamão, correlacionando com os resultados obtidos na pesquisa, por apresentarem maior oferta no mercado e ser de mais fácil acesso a população, tanto em preço quanto em disponibilidade.

Figura 2. Ranking de frutas mais consumidas pelos participantes da pesquisa, em porcentagem (\%). Gráfico elaborado a partir das respostas obtidas na pergunta "Cite cinco frutas que você tem o hábito de consumir, em ordem da mais consumida para a menos consumida?"

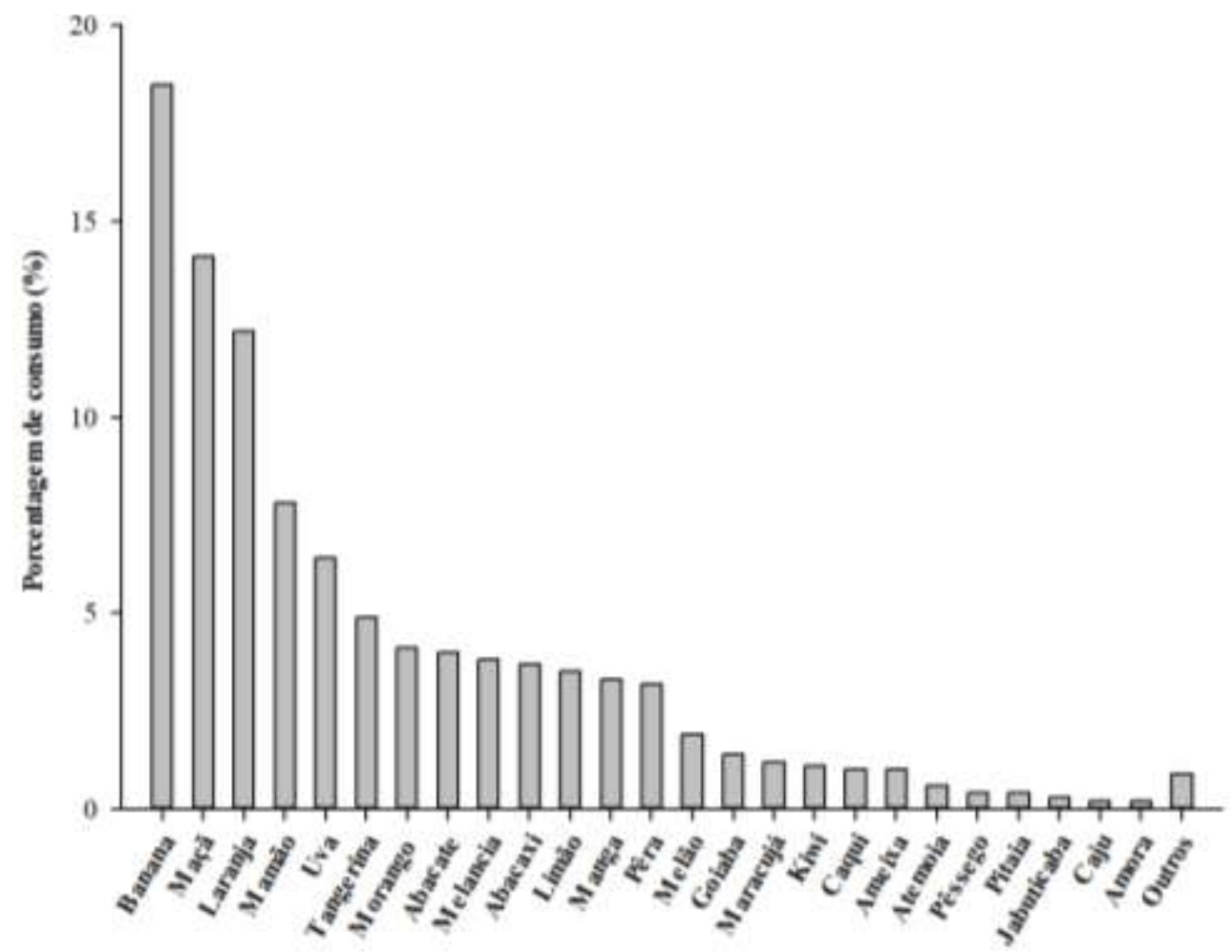

Fonte: Autores.

Do total obtido no presente trabalho apenas 7\% são consideradas nativas do Brasil, tendo apenas o abacaxi, maracujá e goiaba com consumos expressivos. Essas frutas são consideradas as nativas com maiores expressividades no mercado nacional e vem sendo produzidas em larga escala há muitos anos.

Em relação ao local de aquisição pelo consumidor, 50\% dos entrevistados costumam comprar em supermercados, 26\% em mercados especializados (Varejão/Hortifruti) e apenas 15\% visitam feiras livres (Figura 3). Esse padrão vem sendo observado desde a década de 60, com a expansão das cadeias de comercialização de supermercados, sendo que cerca de $50 \%$ do abastecimento de FLV ocorrem através desse canal de vendas, tal crescimento exponencial ocasionou a diminuição de canais de distribuição de alimentos, como feiras e lojas tradicionais, alterando o sistema. Isso ocorreu pela alteração no padrão de consumo exigido pela população, uma vez que o setor supermercadista possui capacidade de atender, manejar e trazer ao consumidor suas expectativas sobre o produto sem que os preços aumentem, mantendo a qualidade esperada (Sato, 2007; Dutra \& Silva, 2017; Maziero et al., 2017). O modo de consumo de frutas in natura prevalece com 59\% dos participantes, como a forma preferível de ingestão, tal fato ocorre, pois, das frutas mais consumidas, a banana e a maçã seguem com $99 \%$ e $80 \%$ do total produzido 
destinado ao consumo in natura e pouco do que se produz é destinado para processamento. O consumo de frutas em forma de bebidas, como o suco, apresentou $31 \%$ da totalidade dos entrevistados, performando-se como um grande potencial para o mercado (Figura 4).

Figura 3. Local de compra de frutas pelos participantes da pesquisa, em porcentagem (\%). Gráfico elaborado a partir das respostas obtida na pergunta "Onde você costuma comprar frutas?"

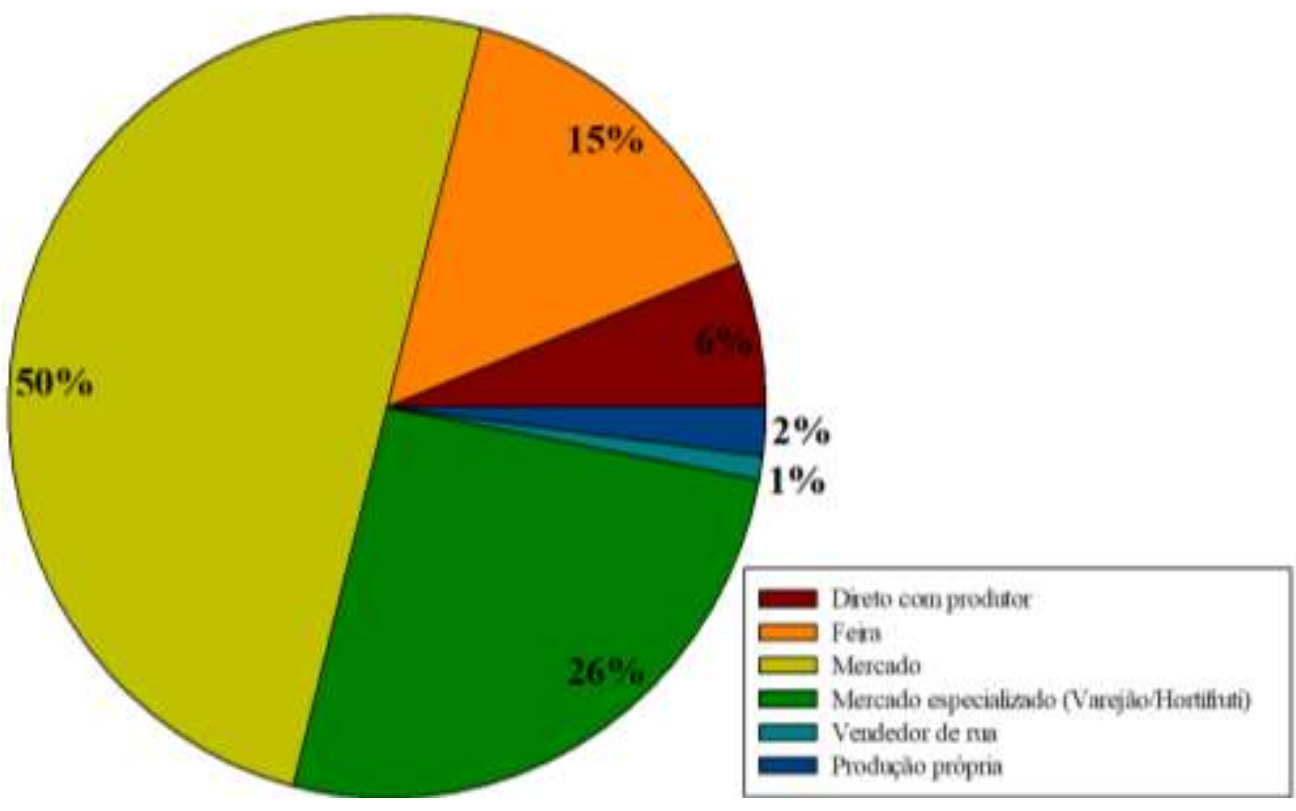

Fonte: Autores.

Figura 4. Modo de consumo de frutas pelos participantes da pesquisa, em porcentagem (\%). Gráfico elaborado a partir das respostas obtida na pergunta "De quais formas você costuma consumir frutas?"

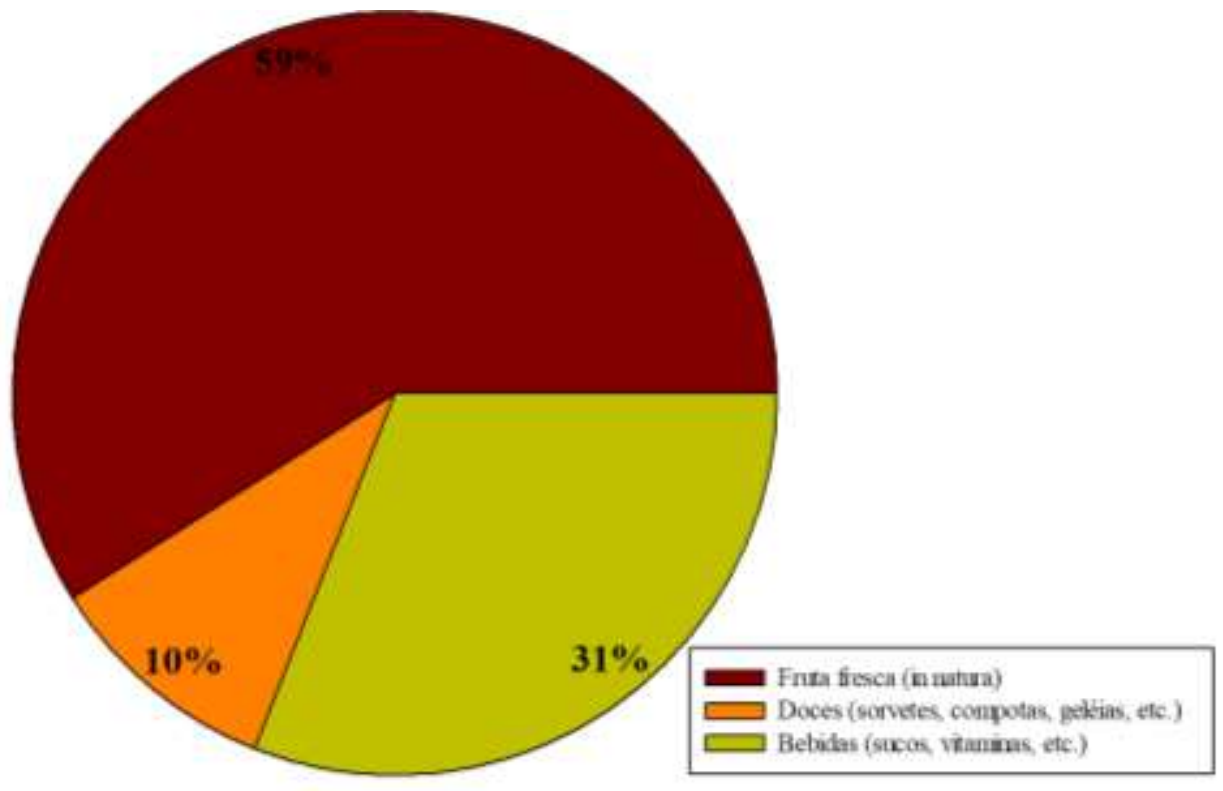

Fonte: Autores.

Quando questionados sobre a familiarização com o termo "frutas exóticas", a maioria dos participantes relatou ter conhecimento do significado (53\%) (Figura 5), entretanto, $45 \%$ não conseguiram definir com exatidão o que seria uma fruta 
exótica e $25 \%$ deixaram de responder a essa pergunta (Figura 6). Porém, foi possível identificar a partir das frutas listadas como exóticas, que a maioria são de origem estrangeira (90\%), o que as classificam como frutas exóticas no país. No entanto, o critério utilizado pela maioria dos entrevistados ao classificar como exótica foi por conta de serem pouco consumidas, ou que tenham aparências e sabores diferentes dos quais estão acostumados encontrar corriqueiramente nas gôndolas dos supermercados, a exemplo da Pitaya, fruta mais citada na pesquisa (Figura 7). Contudo, os conceitos utilizados pelos participantes diferiram-se do biológico, em que frutas exóticas são aquelas que possuem o centro de origem em outros países e foram introduzidas no Brasil, possuindo produção e distribuição nacional (Watanabe \& Oliveira, 2014).

Figura 5. Familiarização do termo "Frutas Exóticas" pelos participantes da pesquisa, em porcentagem (\%). Gráfico elaborado a partir das respostas obtida na pergunta "Você é familiarizado com o termo "Frutas Exóticas"?"

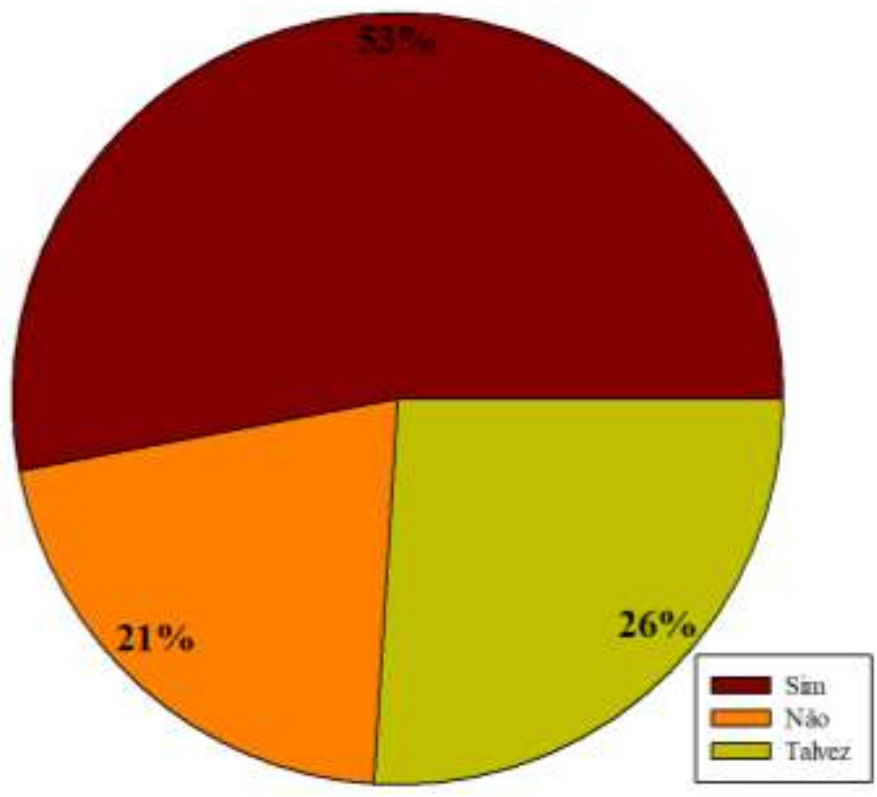

Fonte: Autores. 
Figura 6. Acertos na definição do termo "Exóticas" pelos participantes da pesquisa, em porcentagem (\%). Gráfico elaborado a partir das respostas obtida na pergunta "O que você entende pelo termo "Exóticas"? Cite algumas frutas exóticas que você conhece e consome"

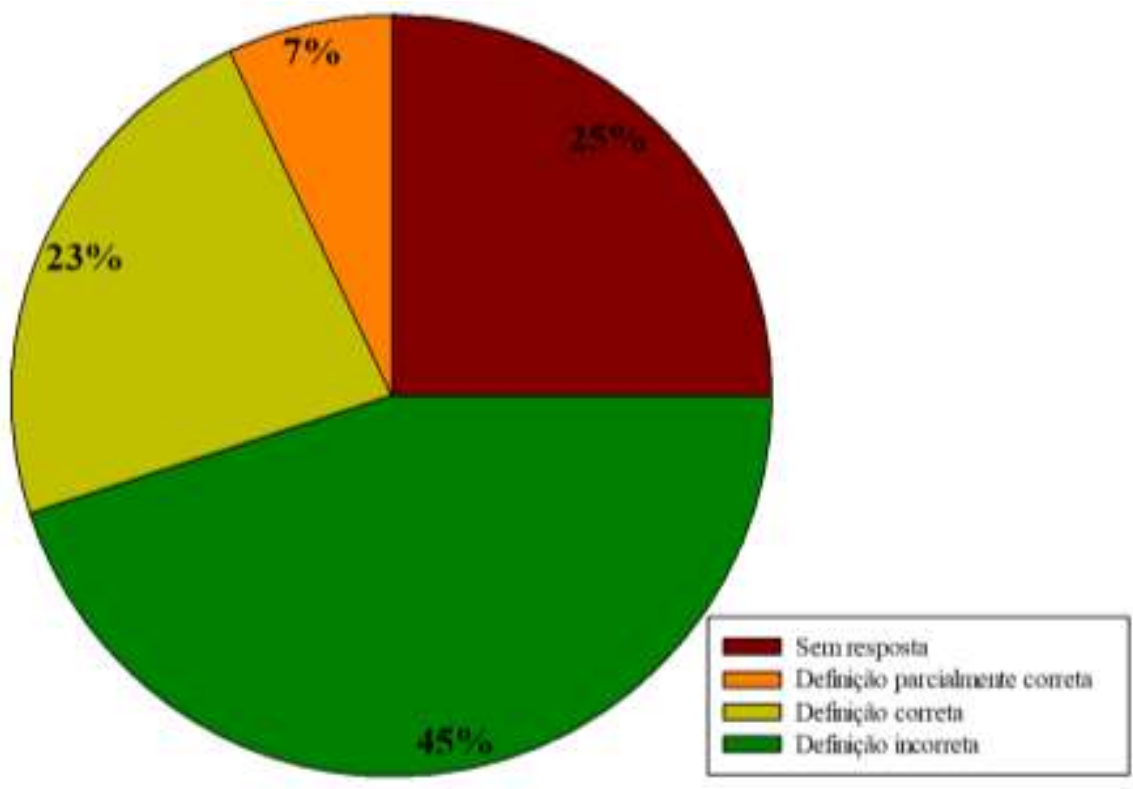

Fonte: Autores.

Figura 7. Ranking de frutas exóticas de conhecimento e consumidas pelos participantes da pesquisa, em porcentagem (\%). Gráfico elaborado a partir das respostas obtida na pergunta "O que você entende pelo termo "Exóticas"? Cite algumas frutas exóticas que você conhece e consome"

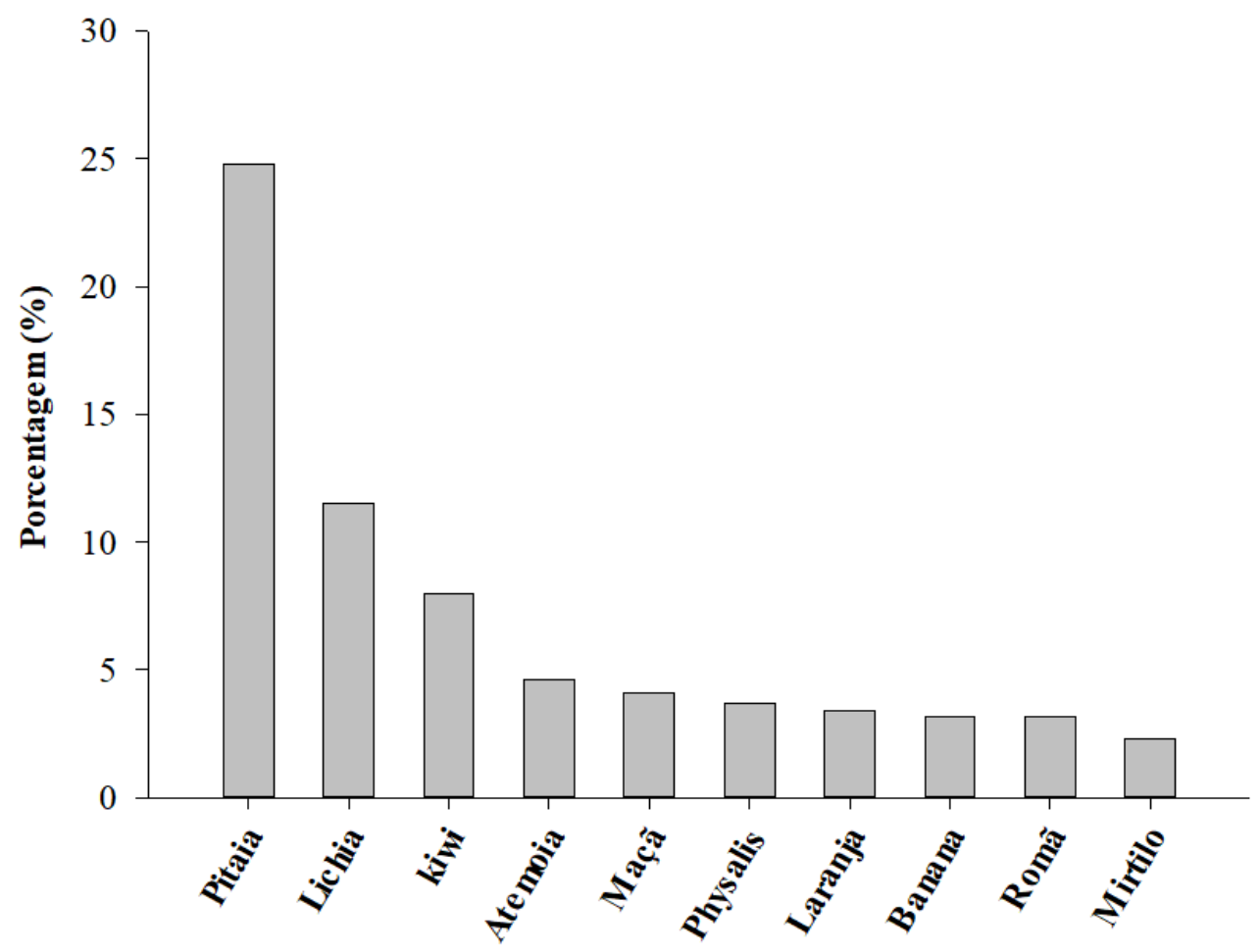

Fonte: Autores.

Espécies nativas são aquelas originadas e encontradas, naturalmente, no território brasileiro, no que se diz respeito ao 
conhecimento sobre a terminologia, a maioria dos participantes (75\%) afirma ser familiarizado com o termo (Figura 8), apesar disso, apenas $45 \%$ dos participantes da pesquisa souberam definir corretamente (Figura 9). No entanto, das frutas listadas pelos participantes, $70 \%$ são consideradas nativas e $30 \%$ exóticas, sendo que acerola e banana, com origem na américa central e sudeste asiático, respectivamente, ocupam o segundo e terceiro lugar no ranking (Figura 10). Apesar da maioria dos entrevistados citar frutas de ocorrência natural no Brasil, ainda persiste certa confusão entre os populares quando questionados quais frutas seriam nativas do território nacional.

Figura 8. Familiarização do termo "Frutas Nativas" pelos participantes da pesquisa, em porcentagem (\%). Gráfico elaborado a partir das respostas obtida na pergunta "Você é familiarizado com o termo "Frutas Nativas"?"

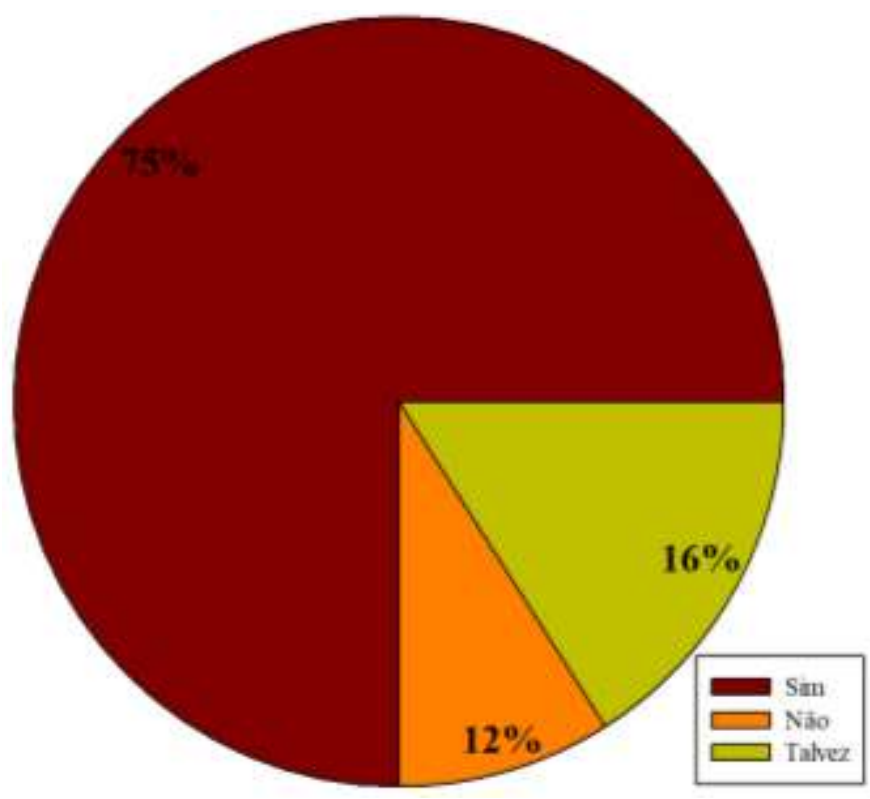

Fonte: Autores.

Figura 9. Acertos na definição do termo "Nativas" pelos participantes da pesquisa, em porcentagem (\%). Gráfico elaborado a partir das respostas obtida na pergunta "O que você entende pelo termo "Nativas"? Cite algumas frutas nativas que você conhece e consome"

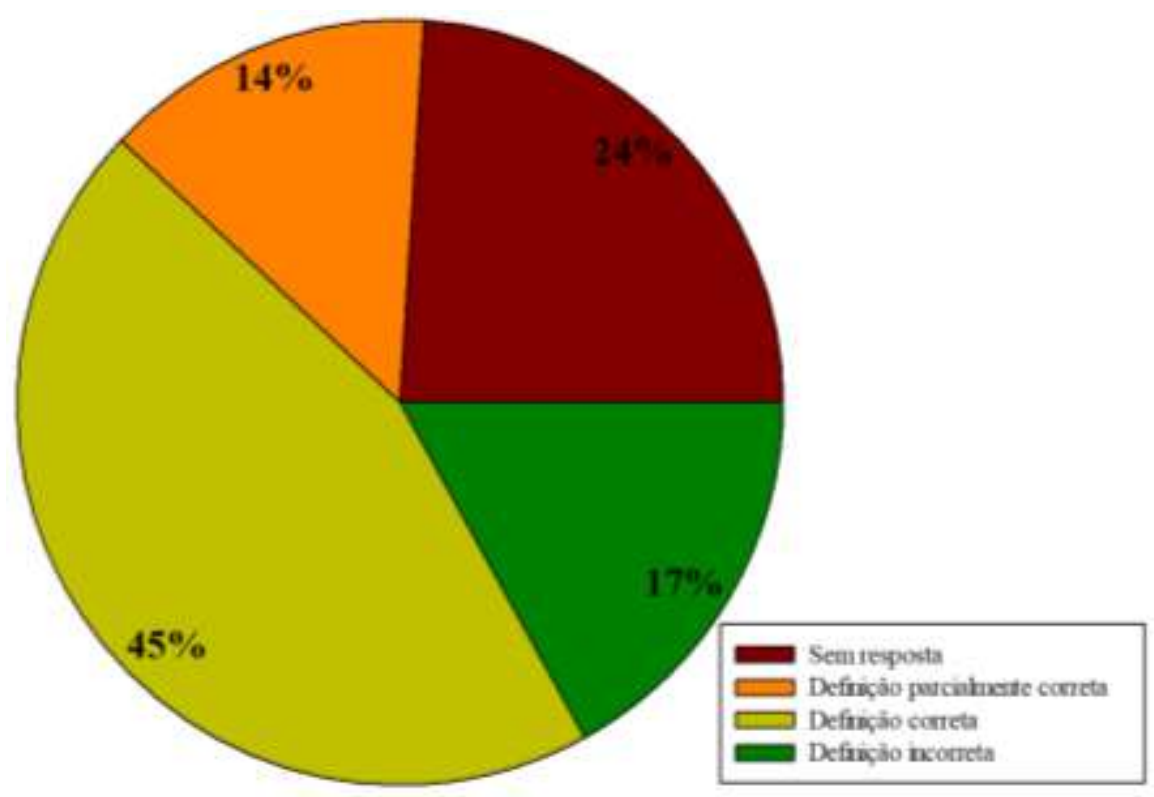


Fonte: Autores.

Figura 10. Ranking de frutas nativas de conhecimento e que são consumidas pelos participantes da pesquisa, em porcentagem (\%). Gráfico elaborado a partir das respostas obtida na pergunta "O que você entende pelo termo "Nativas"? Cite algumas frutas Nativas que você conhece e consome"

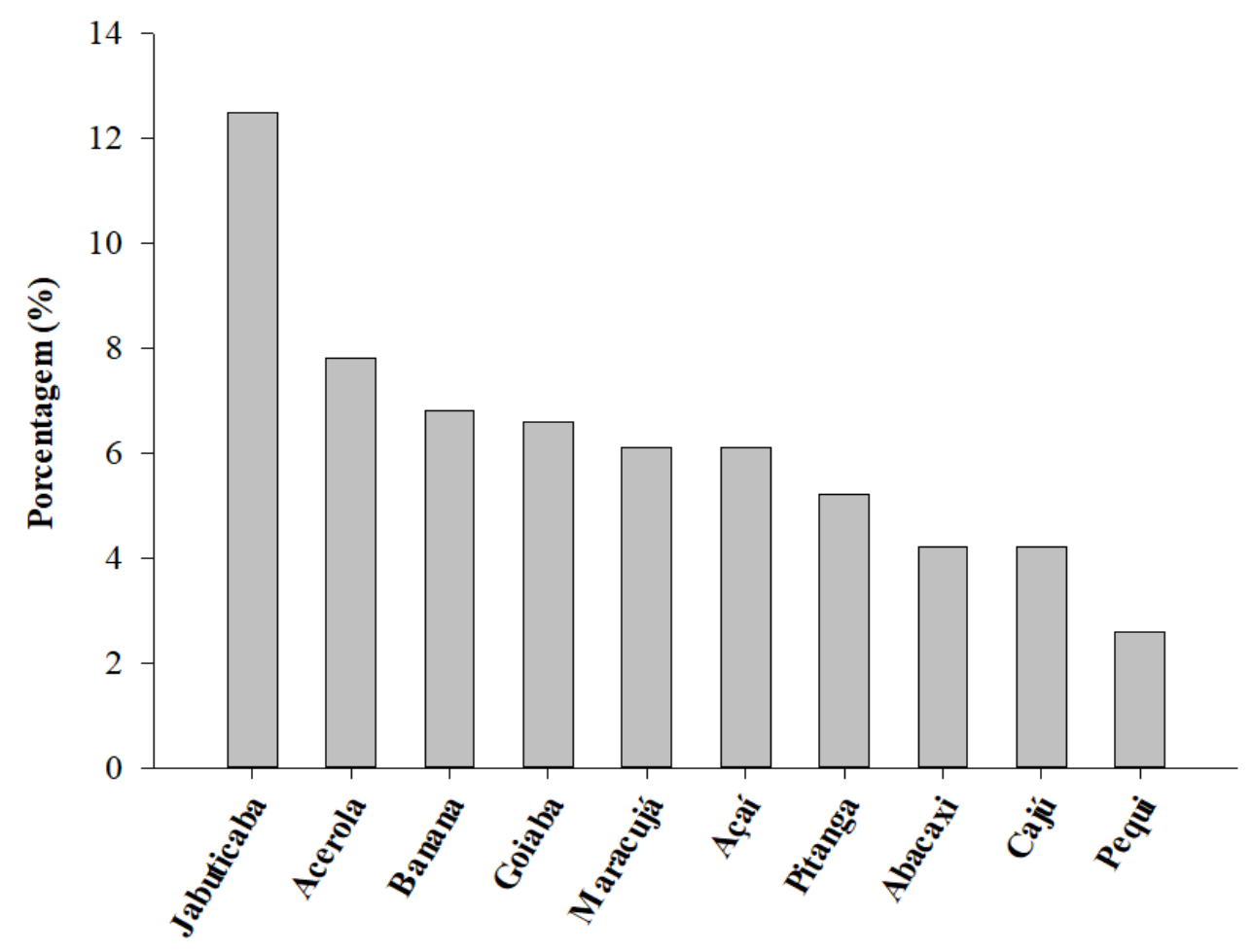

Fonte: Autores.

Na questão relacionada a importância das frutas nativas brasileiras, poucos entrevistados abstiveram suas opiniões, enquanto a maioria demostrou possuir conhecimento sobre o tema, apontando as principais questões em que mostram a relevância das espécies frutíferas nativas para o país. Os principais pontos comentados foram a importância social, econômica, nutracêutica, ambiental, a valorização do produto nacional e a diversificação de produção e consumo, sendo essas as principais questões levantadas em diversos trabalhos científicos encontrados na literatura, a fim de promover a conscientização da população sobre conservação, diversificação, potencialidade e valorização da agrobiodiversidade nacional (Lorenzi, 2014; Lorenzi et al., 2015; Vieira et al., 2016; Alves et al., 2017).

Quando questionados sobre quais seriam os entraves que impedem a inserção das frutas nativas brasileiras no mercado em maiores proporções, os participantes relataram três principais fatores cruciais que afetam negativamente a potencialidade das frutas brasileiras a adentrar ao mercado, sendo a divulgação, incentivo à produção e pesquisas e incentivo ao consumo. De acordo com Kinupp \& Lorenzi (2014) o aproveitamento da agro biodiversidade brasileira depende de vários fatores, entre eles, da existência de técnicas de cultivo, de industrialização dos produtos e, principalmente, da divulgação do conhecimento para a comunidade, que ainda por razões culturais, priorizam culturas exóticas, deixando muitas vezes de lado os próprios recursos naturais brasileiros. Sendo assim, são necessárias intervenções de políticas públicas governamentais que priorizem a criação de programas de popularização do consumo de frutas nativas, como no caso de sucesso do açaí (Meytre Junior et al., 2020), e programas de incentivos à produção e de pesquisas com o objetivo de desenvolver técnicas aprimorando ainda mais a cadeia produtiva das espécies frutíferas brasileiras (Vieira et al., 2006). 
Entre os participantes da pesquisa, apenas $1 \%$ não possui interesse em encontrar facilmente frutas nativas no mercado, 15\% responderam que talvez gostariam, e 84\% demonstraram que teriam tais interesses (Figura 11). Isso demonstra a grande potencialidade de espécies frutíferas nativas de atender a carência de diversificação de frutas nas prateleiras dos canais de distribuição, tornando-se evidente a necessidade do desenvolvimento de trabalhos, não só de divulgação, mas também, pesquisas que estimulem a melhoria da cadeia de produção dessas fruteiras, desde o cultivo à conscientização populacional, permitindo assim maior disponibilidade e fácil acesso aos futuros consumidores, valorizando produtos nacionais e elevando a renda dos produtores rurais.

Figura 11. Potencialidade de consumo de frutas nativas pelos participantes da pesquisa, em porcentagem (\%). Gráfico elaborado a partir das respostas obtida na pergunta "Você gostaria de encontrar facilmente no mercado frutas nativas brasileiras e consumiria com mais frequência?"

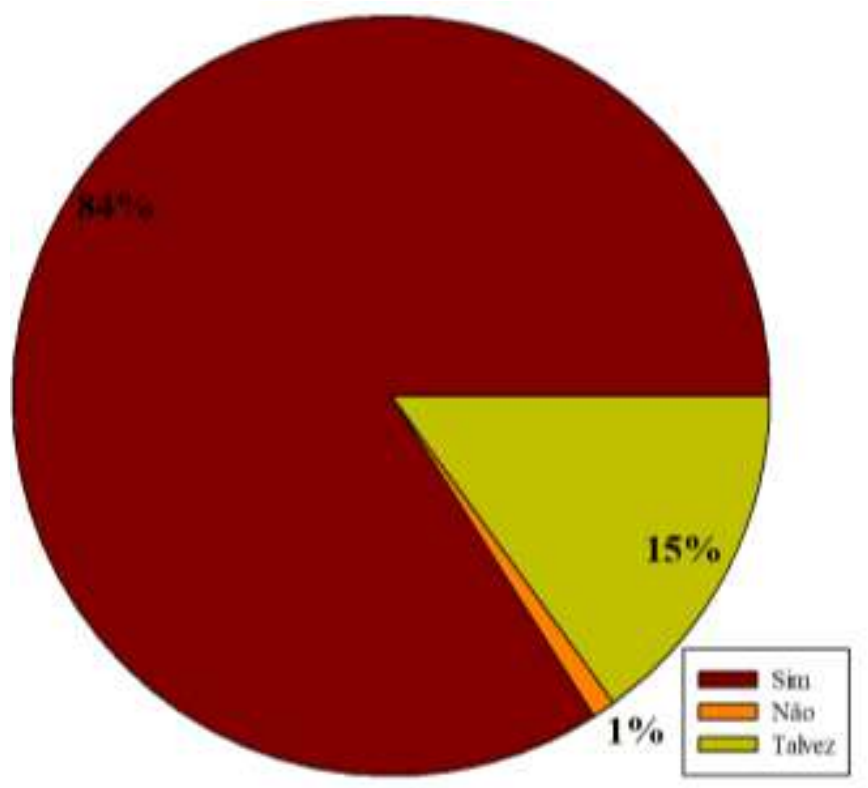

Fonte: Autores.

\section{Conclusão}

O consumo diário de frutas se mantém abaixo do recomendado pela OMS, abrangendo em sua totalidade espécies exóticas comumente produzidas em larga escala, que perfazem o hábito alimentar do consumidor brasileiro, facilmente encontradas nos canais de distribuição, principalmente, em supermercados.

O conhecimento sobre os termos de classificação quanto ao centro de origem permanece confuso, no entanto, há entendimento dos participantes em relação a quais espécies são nativas do Brasil e quais são exóticas.

Os entrevistados possuem consciência da relevância das espécies nativas, compreendem os entraves presentes para a inserção das mesmas no mercado e demonstram interesses em consumir frutas nativas, caso fossem encontradas com mais frequência e quantidade.

\section{Referências}

Anuário Brasileiro de Horti\&Fruti. (2020). http://www.editoragazeta.com.br/sitewp/wp-content/uploads/2020/05/HORTIFRUTI_2020.pdf.

Alves, A. M., Dias, T., Hassimotto, N. M. A. \& Naves, M. M. V. (2017). Ascorbic acid and phenolic contents, antioxidant capacity and flavonoids composition of Brazilian Savannah native fruits. Food Science and Technology, 37 (4), 564-569. doi: 10.1590/1678-457x.26716 
Coradin, L., Siminski, A. \& Reis, A. (2011). Espécies nativas da flora brasileira de valor econômico atual ou potencial: plantas para o futuro - Região Sul. Brasília, DF: MMA.

Dutra, E. G. \& Silva, G. P. (2017). Consumo e abastecimento de frutas e hortaliças em espaços de alimentação comercial e coletiva. Desenvolvimento Regional em Debate, 7 (2), 20-38. doi: 10.24302/drd.v7i2.1459

Fachinello, J. C., Pasa, M. S., Schmtiz, J. D. \& Betemps, D. L. (2011). Situação e perspectivas da fruticultura de clima temperado no Brasil. Revista Brasileira de Fruticultura, 33(spe1), 109-120. doi: 10.1590/S0100-29452011000500014

Food and Agriculture Organization of the United Nations [FAO]. (2020). FAOSTAT. http://www.fao.org/faostat/en/\#data/QC/visualize.

Flora do Brasil 2020. (2020). http://floradobrasil.jbrj.gov.br.

Instituto Brasileiro de Geografia e Estatística [IBGE]. (2018). Diretoria de Pesquisas, Coordenação de Trabalho e Rendimento, Pesquisa de Orçamentos Familiares 2017-2018. https://www.ibge.gov.br/estatisticas/sociais/populacao/24786-pesquisa-de-orcamentos-familiares-2.html?=\&t=o-que-e.

Instituto Brasileiro de Geografia e Estatística [IBGE]. (2017). Produção Agrícola Municipal 2017. https://biblioteca.ibge.gov.br/visualizacao/periodicos/66/pam_2017_v44_br_informativo.pdf.

Kinupp, V. F. \& Lorenzi, H. J. (2014) Plantas Alimentícias Não Convencionais (PANC) no Brasil: guia de identificação, aspectos nutricionais e receitas ilustradas. São Paulo, SP: Editora Plantarum.

Lorenzi, H. (2014). Árvores Brasileiras: manual de identificação e cultivo de plantas arbóreas nativas do Brasil. São Paulo, SP: Editora Plantarum.

Lorenzi, H., Lacerda, M. T. C. \& Bacher, L. B. (2015). Frutas no Brasil nativas e exóticas (de consumo in natura). São Paulo, SP: Editora Plantarum.

Maziero, C. C. S., Jaime, P. C. \& Duran, A. C. (2017). A influência dos locais de refeição e de aquisição de alimentos no consumo de frutas e hortaliças por adultos no município de São Paulo. Revista Brasileira de Epidemiologia, 20 (4), 611-623. doi: 10.1590/1980-5497201700040005.

Meytre Junior, A. G., Oliveira, L. S., Kawamoto Júnior, L. T. \& Machado, S. T. (2020). Desconhecimento e indisponibilidade das frutas nativas da mata atlântica contribuem com hábitos alimentares restritos e sem diversidade. South American Development Society Journal, 6 (17), 269-285. doi:10.24325/issn.24465763.v6i17p269-285.

Rodrigues, D. N. B., Viana, T. V. A., Marinho, A. B., Ferreira, T. T. S., Azevedo, B. M. \& Gomes Filho, R. S. (2012). Fertirrigação potássica na cultura da figueira no semiárido cearense. Revista Brasileira de Agricultura Irrigada, 6 (3), 176-183. doi: 10.7127/rbai.v6n300082.

Rufino, M. S. M., Alves, R. E., Brito, E. S., Pérez-Jimezes, J., Saura-Calixto, F. \& Mancini-Filho, J. (2010). Bioactive compounds and antioxidant capacities of 18 non-traditional tropical fruits from Brazil. Food Chemistry, 121 (4), 996-1002. doi: 10.1016/j.foodchem.2010.01.037.

Santos, K. F. T. D., Santos, M. L. G. T. D., Cella, D., \& Spada, R. K. (2018). FRUTICULTURA: estudo do comércio internacional do mamão. Revista Interface Tecnológica, 15 (2), 323-335. doi: 10.31510/infa.v15i2.499

Sato, L. Processos cotidianos de organização do trabalho na feira livre. (2007). Psicologia \& Sociedade,1, 95-102. doi:10.1590/S0102-71822007000400013.

Silva, L.E.S.; Claro, R.M. Tendências temporais do consumo de frutas e hortaliças entre adultos nas capitais brasileiras e Distrito Federal, 2008-2016. Cad. Saúde Pública 35(5):1-13, 2019. 10.1590/0102-311x00023618.

Souza, B. B., Cembranel, F., Hallal, A. L. C. \& D'orsi, E. (2019). Consumo de frutas, legumes e verduras e associação com hábitos de vida e estado nutricional: um estudo prospectivo em um coorte de idosos. Ciência Saúde coletiva, 24 (4), 1463-1472. doi:10.1590/1413-81232018244.03782017.

Vieira, R. F., Camillo, J. \& Coradin, L. (2016). Espécies nativas da flora brasileira de valor econômico atual ou potencial: plantas para o futuro - Região Centro-Oeste. Brasília, DF: MMA.

Vieira, R. F., Costa, T. S. A., Silva, D. B., Ferreira, F. R. \& Sano, S. M. (2006). Frutas Nativas da Região Centro-Oeste do Brasil. Brasília, DF: Embrapa Recursos Genéticos e Biotecnologia.

Watanabe, H. S., Oliveira, S. L. (2014). Comercialização de frutas exóticas. Revista Brasileira de Fruticultura, 36 (1), 23-38. doi: 10.1590/0100-2945-443/13. 